\title{
Características Físico-Químicas del Látex de Papayuelo (Vasconcellea cundinamarcensis Badillo, Caricaceae)
}

Leslie V. Vidal ${ }^{1}$, Víctor L. Finot ${ }^{2}$, Karina del C. Mora ${ }^{1}$ y Fernando A. Venegas ${ }^{3}$

Universidad de Concepción, (1) Facultad de Ingeniería Agrícola, Departamento de Agroindustrias, Facultad de Agronomía, (2) Departamento de Producción Animal, (3) Departamento de Producción Vegetal, Casilla 537, Chillán-Chile (e-mail: Ividal@udec.cl, vifinot@udec.cl, fervenegas@udec.cl)

\begin{abstract}
Resumen
Se determinó el rendimiento y la actividad enzimática de la papaína presente en el látex de papayuelo (Vasconcellea cundinamarcensis), cultivado en Cobquecura, VIII región del Bío-Bío, Chile, durante un año. Entre enero y diciembre, las plantas, frutos y látex, obtenidos de frutos inmaduros, fueron caracterizados con el propósito de conocer el comportamiento del cultivo a través de las estaciones del año, y comprender las posibles relaciones entre los parámetros estudiados. El diseño experimental fue completamente aleatorio y los datos se procesaron mediante un ANDEVA y prueba de rangos múltiples de Duncan. Se encontró diferencia estadística significativa entre estaciones en cuanto al desarrollo de la planta y sus características. Los mayores rendimientos de látex se obtuvieron en la estación de primavera, mientras que la actividad enzimática se mantuvo constante durante el año de estudio.
\end{abstract}

Palabras clave: papaína, actividad enzimática, Vasconcellea cundinamarcensis, papayuelo látex

\section{Physico-Chemical Characteristics of Papayuelo Latex (Vasconcellea Cundinamarcensis Badillo, Caricaceae)}

\begin{abstract}
A study to determine the yield and enzymatic activity of papain present in the latex obtained from papayuelo fruit (Vasconcellea cundinamarcensis ) cultivated in Cobquecura, VIII Bío-Bío Region in Chile, during one year was done. Between January and December the papayuelo plants, fruits and latex obtained from unripe fruits were characterized. The objective of the study was to know the species behavior through the seasons and the relation between the parameters studied. The experimental design was completely random, and the data were processed through ANOVA and Duncan's multiple range test. A significant statistical difference in plant growth and plan characteristics between seasons was found. The higher latex yields were obtained in spring, whereas the enzymatic activity was constant through the year.
\end{abstract}

Keywords: papain, enzymatic activity, Vasconcellea cundinamarcensis, papayuelo latex

Información Tecnológica Vol. - 20 Nº 6 - 2009 


\section{INTRODUCCION}

La familia Caricaceae comprende seis géneros y 35 especies (Kyndt et al., 2005). La especie económicamente más importante es el papayo, Carica papaya L. (Badillo, 1993, 2000; Teixeira et al., 2008). En Chile sólo se cultiva comercialmente Vasconcellea cundinamarcensis [= Carica pubescens (DC) Solms-Laub.], conocida como "papayuelo" (debido a su semejanza con la papaya), o "papayo de montaña" (debido a su preferencia ecológica por las regiones montañosas), aunque en Chile suele denominársele también "papayo".

El género Vasconcellea, considerado previamente una sección del género Carica, fue rehabilitado por Badillo $(2000,2001)$, sobre la base de caracteres morfológicos y genéticos. La validez del género Vasconcellea ha sido confirmada por estudios de divergencia genética entre ambos géneros, la que fluctúa entre 73 y 77\% (Jobin-Decor et al., 1997; Kyndt et al., 2005; Van Droogenbroeck et al., 2004). Con 21 de las 35 especies de Caricaceae, Vasconcellea es el mayor de los seis géneros de la familia y su distribución se extiende a lo largo de la Cordillera de Los Andes en Sudamérica, con una concentración de especies en Ecuador, donde habitan 16 especies, desde el nivel del mar hasta cerca de los $3.500 \mathrm{~m}$ (Kyndt et al., 2005). Vasconcellea cundinamarcensis se extiende desde Colombia hasta Bolivia en forma natural y como planta cultivada alcanza el centro-sur de Chile, donde se cultiva en localidades costeras, libres de heladas y protegida de los vientos, entre la IV y la VIII Región (Quintanilla, 1995). Cobquecura, VIII Región del Bío-Bío, es la localidad más austral del cultivo de esta especie.

Vasconcellea cundinamarcensis es una planta arborescente que desarrolla tres tipos de flores: femeninas, masculinas y hermafroditas (Badillo, 2000; Kiger, 1988). Existen árboles masculinos, árboles femeninos y árboles con flores hermafroditas (Buzeta y Eyheralde, 1982). Se distingue de otros frutales cultivados en Chile, por su hábito herbáceo, su precocidad, por la producción continua a través del año y por el bajo costo de producción (Buzeta y Eyheralde, 1982).

El fruto es una baya ovoide, de 7-10 cm de largo por 3-6 cm de ancho, con cinco lóbulos que se corresponden con los cinco carpelos del ovario. Los frutos de flores femeninas tienden a ser globosos, mientras que los provenientes de flores hermafroditas son alargados, piriformes y con surcos más pronunciados entre los lóbulos, como ocurre también en el papayo tropical, Carica papaya (Buzeta y Eyheralde, 1982). Los frutos se utilizan principalmente para la elaboración de conservas y para la producción de papaína, enzima proteolítica presente en el látex exudado al practicar un corte superficial a hojas, tallos y frutos (Quintanilla, 1995; Yagnam, 1996). El látex tratado y deshidratado, adquiere el aspecto de polvo blanquecino o café claro que se denomina papaína cruda, semirrefinada o refinada según su pureza y tratamiento (Yagnam, 1996).

La papaína es una enzima estable y de amplia especificidad, que le permite degradar proteínas de distinta naturaleza y en una extensión superior a otras enzimas proteolíticas, características que favorecen su empleo en preparaciones farmacéuticas (Gomes et al., 2008) que se utilizan para descongestionar las vías respiratorias, en el tratamiento de lesiones traumáticas o inflamatorias, en la degradación de proteínas para consumo humano (Vega, 1977) y en la industria cosmética como suavizante dermatológico y revitalizador facial. En la industria alimentaria se utiliza como ablandador de carnes (Larson et al., 2008) y clarificador de cerveza entre otros usos (Kiger, 1988). La naturaleza no específica del grupo de proteasas contenidas en la papaína, que permite la digestión de diferentes sustratos, sumada a la facilidad de extracción y producción, explican la actual expansión del mercado de la papaína (Baeza et al., 1990).

Los objetivos de la presente investigación fueron caracterizar las plantas en cuanto a crecimiento y producción de frutos, y determinar rendimiento y actividad enzimática del látex de papayuelo cultivado en Cobquecura, VIII Región del Bío-Bío, Chile, en las diferentes estaciones del año 2003.

\section{METODOLOGÍA}

El estudio se realizó en un huerto ubicado en Cobquecura, Provincia de Ñuble, VIII Región $\left(36^{\circ} 06^{\prime} \mathrm{S}\right.$, $\left.72^{\circ} 47^{\prime} \mathrm{W}\right)$, con una superficie de 0.3 há. El sistema de plantación fue en camellón con dos hileras en 
zig-zag, un marco de plantación de 1,2 x 1,2 m sobre y entre hileras y $4 \mathrm{~m}$ entre camellones; la densidad de plantación fue de 4.166 plantas $\mathrm{ha}^{-1}$.

El huerto fue manejado con riego por goteo y cuenta con aspersores para evitar daño por heladas, así como una cortina de árboles como protección contra el viento. El suelo de los camellones presentó textura franca, mientras el resto del terreno es de textura franco-arcillosa. La densidad aparente fue de $1,3 \mathrm{~g} \mathrm{cc}^{-1}$ y el pH de suelo de 6,39, parámetros adecuados al rango de adaptación de la especie (Sudzuki, 1996). Se detectó un bajo nivel de materia orgánica (4\%) y de K, lo cual explica la clorosis y márgenes necrosados en hojas, así como defoliación prematura (Sudzuki, 1996); no se detectó síntomas adicionales de deficiencia nutricional; se detectó infestación leve con nemátodos fitoparásitos.

Se escogieron 10 plantas de 2-3 años de edad, a las cuales se les identificó el sexo, para establecer diferencias en producción y tamaño de fruto entre plantas hembras y hermafroditas. Los tipos florales presentes se determinaron siguiendo a Badillo (1993), como se describe en la Tabla 1.

Tabla 1: Formas florales descritas para Vasconcellea cundinamarcensis.

\begin{tabular}{|l|c|c|c|c|}
\hline \multirow{2}{*}{ Tipo de flor } & \multicolumn{4}{|c|}{ Características } \\
\cline { 2 - 5 } & corola & tubo & estambres & pistilo \\
\hline Femenina & dialipétala & ausente & ausentes & $\begin{array}{c}\text { presente, ovario bien } \\
\text { desarrollado }\end{array}$ \\
\hline $\begin{array}{l}\text { Pistilada } \\
\text { carpeloide (frutos } \\
\text { deformes) }\end{array}$ & gamopétala & $\begin{array}{c}\text { Corto o } \\
\text { nulo }\end{array}$ & $\begin{array}{c}1 \text { a } 5 \text { (4 } \\
\text { carpeloides) }\end{array}$ & $\begin{array}{c}\text { ovario alto, estilo corto, } \\
\text { estigma con 1 a 4 } \\
\text { ramas }\end{array}$ \\
\hline $\begin{array}{l}\text { Estaminada } \\
\text { carpeloide (no } \\
\text { fructifica) }\end{array}$ & gamopétala & presente & $\begin{array}{l}10,5-9 \text { libres, el } \\
\text { resto fusionado }\end{array}$ & $\begin{array}{c}\text { ovario sin tejido } \\
\text { esporógeno y estigma } \\
\text { filiforme infértil }\end{array}$ \\
\hline Masculina & gamopétala & presente & $\begin{array}{c}10 \text { estambres } \\
\text { libres }\end{array}$ & rudimentario \\
\hline
\end{tabular}

Cinco plantas de las diez en estudio se utilizaron tanto para su caracterización como para el estudio del rendimiento y la actividad enzimática de látex; las cinco restantes, se destinaron a las mediciones de contenido de humedad, masa y composición química de fruto. Todas las mediciones se repitieron cada 15 días.

Para la caracterización de las plantas se tuvieron en cuenta la altura medida en $\mathrm{m}$, desde el suelo hasta la última hoja; y el diámetro de tronco, el cual se midió en $\mathrm{cm}$ a nivel del suelo. Para cuantificar y determinar el número de frutos éstos se contaron según las categorías de tamaño descritas en la Tabla 2. Se determinó la proporción de frutos verdes, pequeños y maduros en cada árbol, quincenalmente.

Tabla 2: Categorías de fruto establecidas para discriminar entre frutos aptos (Clase I) y no aptos (Clase II y III) para extracción de látex.

\begin{tabular}{|l|c|c|c|}
\hline \multirow{2}{*}{ Características } & \multicolumn{3}{|c|}{ Categoría } \\
\cline { 2 - 4 } & Clase I & Clase II & Clase III \\
\hline Tamaño $(\mathrm{mm})$ & $>60$ & $<60$ & Cualquier tamaño \\
\hline Color & verde & verde & $\begin{array}{c}\text { verde con tonalidades } \\
\text { amarillas }\end{array}$ \\
\hline
\end{tabular}

La caracterización de los frutos verdes se llevó a cabo en las plantas previamente utilizadas para ser caracterizadas. Se escogieron de las plantas seleccionadas cinco frutos verdes al azar para la caracterización de los mismos. Se les midió, utilizando vernier digital, largo y diámetros mayor (ancho) y menor (alto). El largo es la medida longitudinal entre ambos polos del fruto. Para 
determinar los diámetros, se tomaron dos medidas transversalmente en la zona ecuatorial del fruto. Además se determinó color mediante tabla Munsell (Munsell, 1963).

Para la extracción de látex en frutos clasificados en Clase I, se hicieron 3-4 cortes longitudinales (no mayores que $3 \mathrm{~mm}$ de profundidad). El látex exudado fue recogido en una probeta graduada mediante un embudo. El rendimiento se determinó volumétricamente.

Para caracterizar el látex se determinó la densidad, el color por comparación con tabla Munsell, contenido de materia seca por gravimetría en estufa a $70^{\circ} \mathrm{C}$, contenido de sólidos solubles cuantificados mediante refractometría, $\mathrm{pH}$, acidez titulable evaluada mediante técnica volumétrica, contenido de proteína medida espectrofotométricamente por técnica de Bradford (Bradford, 1976), proteína Kjeldahl (Hart y Fischer, 1971) y actividad enzimática realizada por técnica titulométrica (Worthington Biochemical Corporation, 1993). Todas las determinaciones fueron estandarizadas según la AOAC (AOAC, 1995). El análisis de fruto verde se llevó a cabo en cinco árboles escogidos aleatoriamente. De cada uno se extrajo al menos dos frutos, en los cuales se determinaron los parámetros físico-químicos mencionados. Además, se realizó un análisis proximal Wende (Hart y Fischer, 1971).

\section{RESULTADOS Y DISCUSION}

\section{Caracterización de las plantas}

El crecimiento de las plantas se manifestó tanto en un incremento de la altura como en el diámetro de tronco, existiendo entre ambos parámetros una correlación positiva. Si bien, este crecimiento no mostró diferencia estadística $(P \leq 0,05)$ entre estaciones, la tendencia es clara al observar gráficamente los cambios ocurridos en la planta mes a mes (Fig. 1 y 2). Entre enero y julio el crecimiento es prácticamente nulo, sin embargo, manifiesta un claro aumento a partir del mes de agosto (fines de invierno-principios de primavera). El diámetro de tronco, tampoco mostró diferencia estadística significativa entre estaciones. Este parámetro se correlaciona positivamente con los números de frutos verdes (Clase I), maduros (Clase III), como así también, con el número total de frutos por planta. Dichas correlaciones indican, consecuentemente, un mayor rendimiento de látex.

En cambio, se observó una correlación negativa para frutos Clase II (pequeños) y actividad enzimática de fruto, con el diámetro de tronco y altura de las plantas, mostrando que en plantas pequeñas se encuentran mayoritariamente frutos Clase II, inadecuados para la extracción de látex. Esto confirma, que en plantas con mayor desarrollo se obtienen los mayores rendimientos de látex, lo cual se corrobora con los resultados de esta investigación, Las plantas con mayor desarrollo presentaron los mayores rendimientos de látex, lo cual se observó en primavera, pues el látex se produce en toda la planta, por lo tanto, mientras más grande sea ésta, mayor es su producción

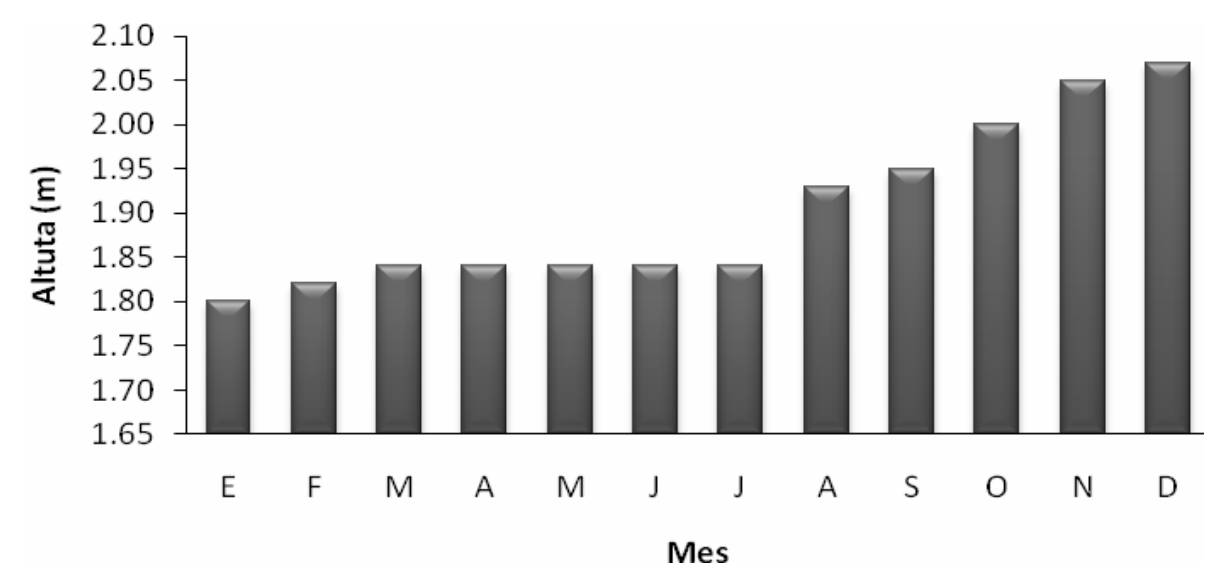

Fig. 1: Altura (m) de plantas de papayuelo durante la temporada 2003. 


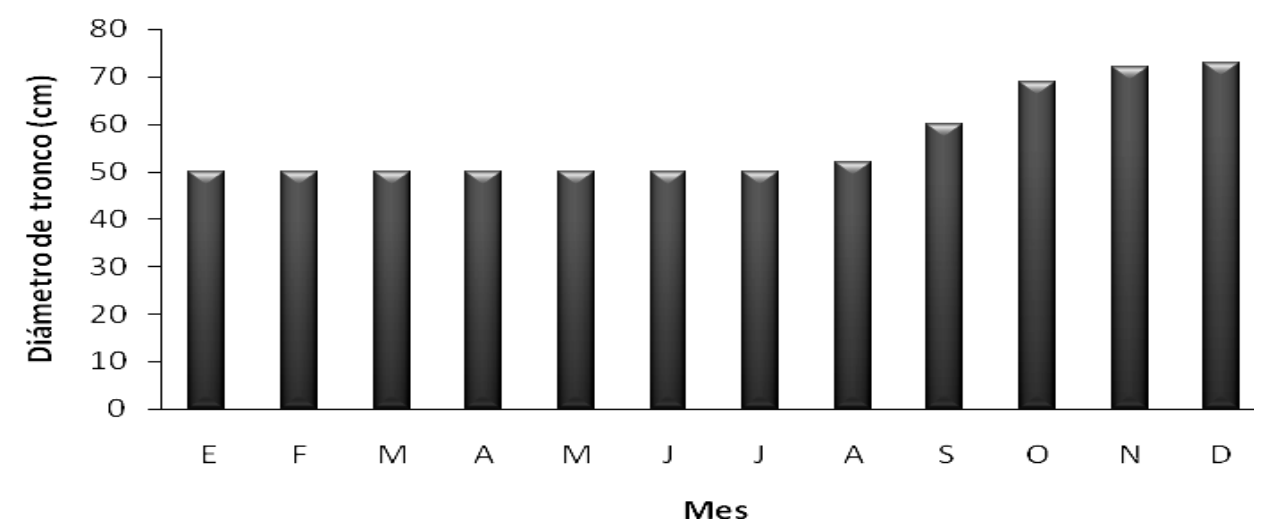

Fig. 2: Diámetro de tronco $(\mathrm{cm})$ de plantas de papayuelo durante la temporada 2003

\section{Producción de frutos}

Se encontró diferencia estadísticamente significativa $(P \leq 0,05)$ en el número de frutos totales a través de las estaciones, así como en la proporción de frutos verdes (Clase I), maduros (Clase III) y pequeños (Clase II), presentes en la planta según la época del año. El test de rangos múltiples de Duncan (Montgomery y Runger, 1998) muestra que esta diferencia ocurre entre fines de agosto, cuando se registró la media más alta $\left(60,8\right.$ frutos verdes árbol $\left.{ }^{-1}\right)$ y los meses de abril-mayo, momentos en que se produjo ausencia de frutos verdes aptos para la extracción de látex. El mismo test aplicado a los datos, esta vez agrupados por estación, también encontró diferencia significativa entre estaciones como se indica en la Tabla 3.

Tabla 3: Distribución estacional (año 2003) del número de frutos verdes por planta presentes en papayuelo (Vasconcellea cundinamarcensis), cultivado en Cobquecura, Región del Bíobío, Chile. Letras distintas en sentido vertical indican diferencia estadística significativa ( $P \leq 0,05)$.

\begin{tabular}{|l|c|}
\hline Estación & Promedio \\
\hline Otoño & $0,93 \mathrm{D}$ \\
\hline Invierno & $31,81 \mathrm{~B}$ \\
\hline Primavera & $52,77 \mathrm{~A}$ \\
\hline Verano & $12,61 \mathrm{C}$ \\
\hline
\end{tabular}

En cuanto a la proporción de frutos verdes (Clase I), según el test de rangos múltiples de Duncan, ésta es significativamente menor en otoño y similar en las estaciones de invierno, primavera y verano. Este parámetro se correlaciona positivamente con el rendimiento y la actividad enzimática de látex. La proporción de frutos pequeños (Clase II) es mayor en otoño (85,3\%), momento a partir del cual comienza a disminuir para repuntar en la estación de verano. Los frutos maduros (Clase III), en tanto, se concentran en verano $(11 \%)$ y se mantienen en un bajo porcentaje durante el resto de las estaciones, en un rango de 0,4 a $3,6 \%$ del total de frutos (Fig. 3). Esto indica que otoño es la estación donde se registra la menor proporción de frutos verdes aptos para extracción de látex, y al mismo tiempo, la mayor proporción de frutos pequeños, es decir, en esa estación los frutos están en crecimiento, por lo que es una época inadecuada para extraer látex. La mejor época para extraer látex en cuanto al rendimiento por árbol es primavera. La maduración de los frutos se concentra en verano, ya que está relacionada directamente con un aumento en las temperaturas, por tratarse de un fruto típicamente climatérico (Sudzuki, 1996).

\section{Caracterización de frutos}

El fruto expresa su crecimiento con un aumento en el largo y diámetros mayor y menor (Fig. 4). Estas medidas aumentan en la misma proporción a través del tiempo. En la estación de verano el largo promedio de los frutos fue aproximadamente de $100 \mathrm{~mm}$, para disminuir en otoño, hasta poco más de $60 \mathrm{~mm}$ y aumentar, primero lentamente en invierno y luego a razón de $10 \mathrm{~mm}$ por mes en 
primavera para alcanzar los $100 \mathrm{~mm}$ promedio en el verano de la temporada siguiente. Estos cambios son estadísticamente significativos $(P \leq 0,05)$.
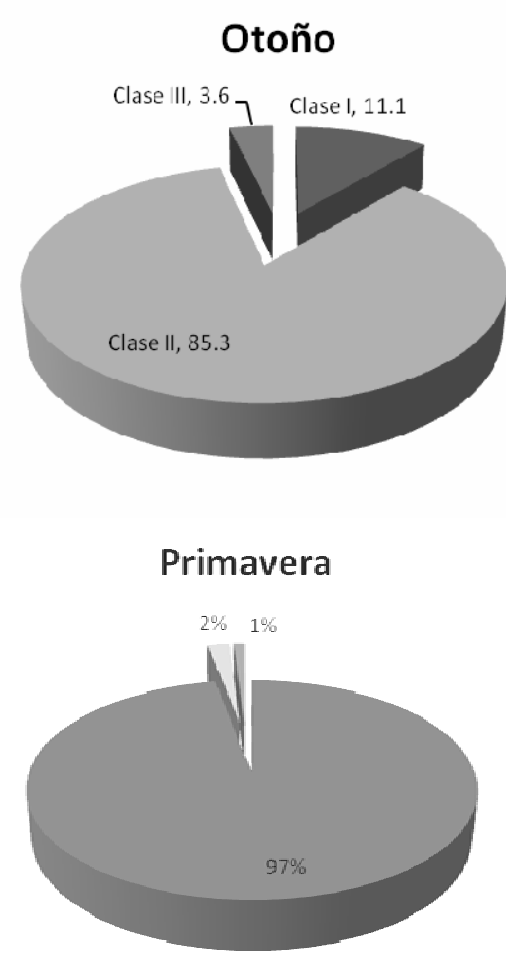
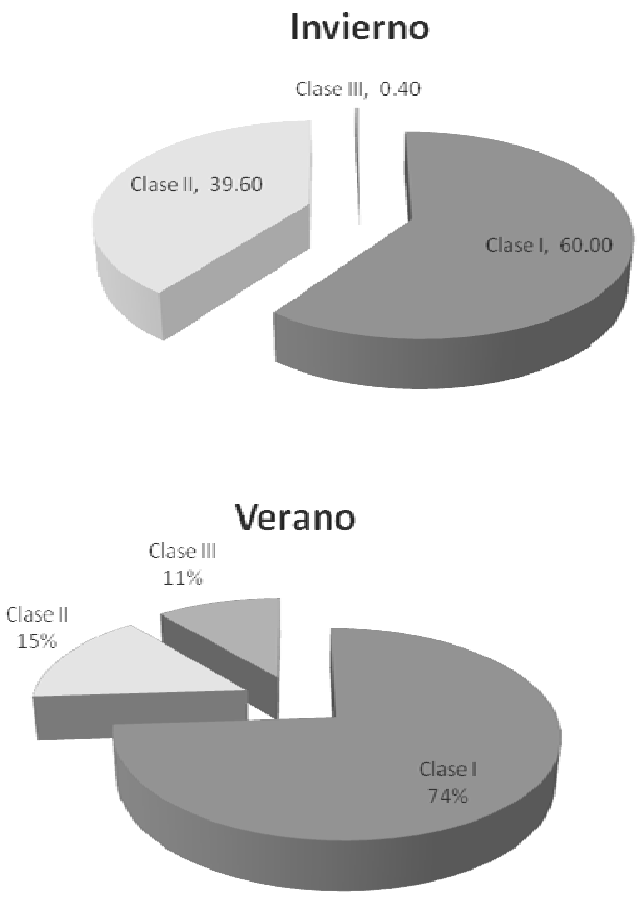

Fig. 3: Proporción de frutos Clase I (verdes), Clase II (pequeños) y Clase III (maduros) presentes en la planta de papayuelo a través del tiempo.

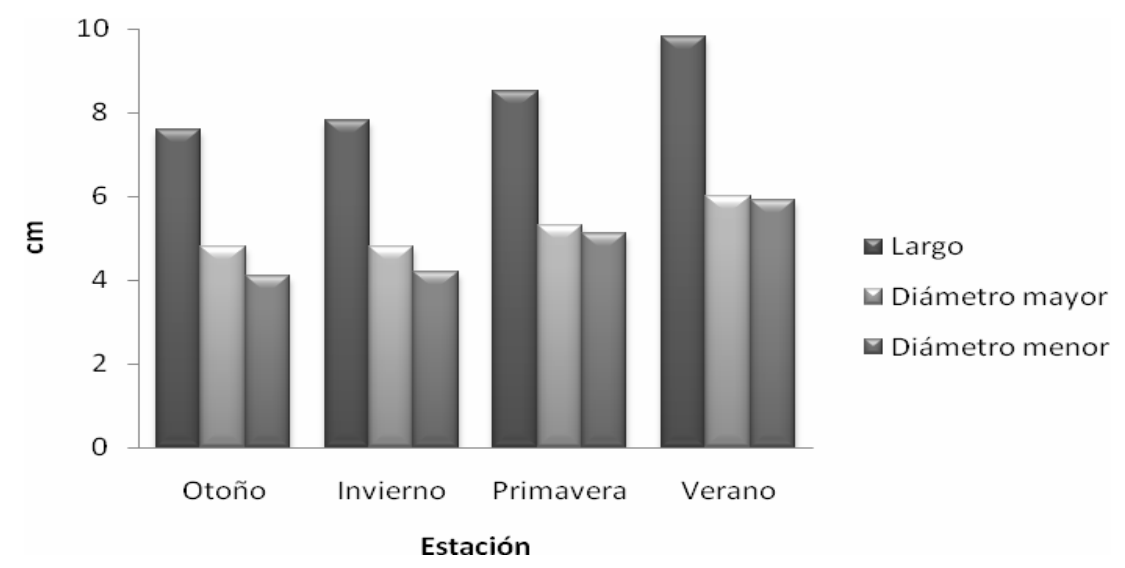

Fig. 4: Largo y diámetro mayor de fruto verde de papayuelo a través del tiempo, expresado en mm.

Según el análisis de correlación, a medida que los frutos incrementan su tamaño aumenta la acidez, el látex tendrá mayor contenido de sólidos solubles y la planta en la cual se encuentran tendrá menor número de frutos totales. La técnica de raleo (Chavarro et al., 2006) de frutos establece que al disminuir la carga frutal puede aumentar el calibre de los frutos, dado que las reservas se concentrarán en nutrir mejor los frutos que quedan. Sin embargo, Acosta-Zamudio et al. (1999) no encontraron un aumento en el tamaño de los frutos al disminuir la carga frutal sobre la respuesta de plantas de papayuelo tipo 'Cera' y 'Sunset Solo', a diferente número de frutos por planta, evidenciando que la biomasa podría distribuirse hacia la raíz, puesto que tampoco hubo aumento de biomasa en tallos ni hojas. 


\section{Extracción de látex}

El rendimiento de látex resulta de la conjugación de los factores: volumen de látex promedio por fruto, número de frutos verdes promedio por árbol y número de árboles por hectárea. Así se obtiene el rendimiento de látex por hectárea. Los factores inherentes al comportamiento de la planta, y por lo tanto, estudiados en esta investigación, se correlacionan positivamente y mostraron diferencia estadística significativa entre estaciones según el análisis de varianza. Para el caso de rendimiento de látex por fruto, y según el test de rangos múltiples de Duncan, los meses de enero-febrero registraron el rendimiento más alto, del orden de $0,7 \mathrm{~mL} /$ fruto $\left(4-6 \mathrm{~mL}\right.$ árbol ${ }^{-1}$ promedio). El resto del año, y como se pudo comprobar en terreno, los rendimientos son muy bajos, llegando incluso a cero en la estación de otoño, lo que coincide con el bajo número de frutos verdes presentes en esa época. El rendimiento de látex, como ocurre con otros productos, depende de numerosas variables incluyendo el factor ambiental, el cual no se puede manejar y no se abordó en este estudio. Se puede concluir, entonces, que es determinante, en el rendimiento de látex de papayuelo cultivado en Cobquecura, el número de frutos verdes presentes en la planta en el momento de la extracción, cuya máxima expresión se da en primavera y como lo muestra la Fig. 5, el rendimiento por árbol, y finalmente por hectárea es mayor en esa época del año. Aunque en los meses de invierno la actividad enzimática no disminuye, el número de frutos no hace sustentable este recurso en esa época del año.

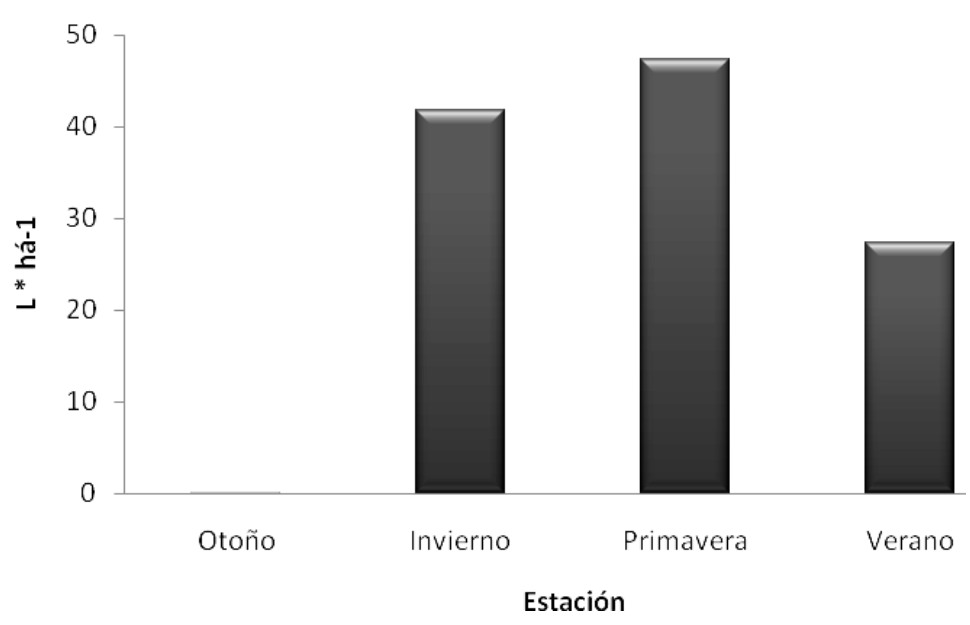

Fig. 5: Rendimiento de látex por fruto $(\mathrm{mL})$ en las distintas estaciones del año

Las características del látex reflejaron un comportamiento homogéneo a través del tiempo, lo que reviste especial importancia al proyectar una posible extracción industrial. La densidad, el color, la materia seca, los sólidos solubles, el pH, la acidez titulable y la actividad enzimática no mostraron variaciones importantes en el tiempo (Fig. 6). La actividad enzimática de látex fue mayor en aquellos árboles con mayor número de frutos verdes, según análisis de correlaciones.

Ninguno de estos parámetros presentó diferencia estadística significativa entre estaciones según ANDEVA, como se muestra en la Tabla 4. Para fines comerciales, la mejor época de extracción, en cuanto al rendimiento es primavera, mientras que la actividad enzimática se mantiene alta durante todo el año.

\section{Análisis de fruto}

Como se observa en la Tabla 5, las características del fruto verde, al igual que en el caso del látex, son muy uniformes durante todo el año, no mostrando diferencia significativa entre estaciones, a excepción de la materia seca, que muestra un significativo incremento en la estación de verano. El fruto de papayuelo es una baya proveniente de un ovario súpero, de pericarpio carnoso y suculento, cuyo color puede variar desde el verde en otoño al amarillo en verano. 


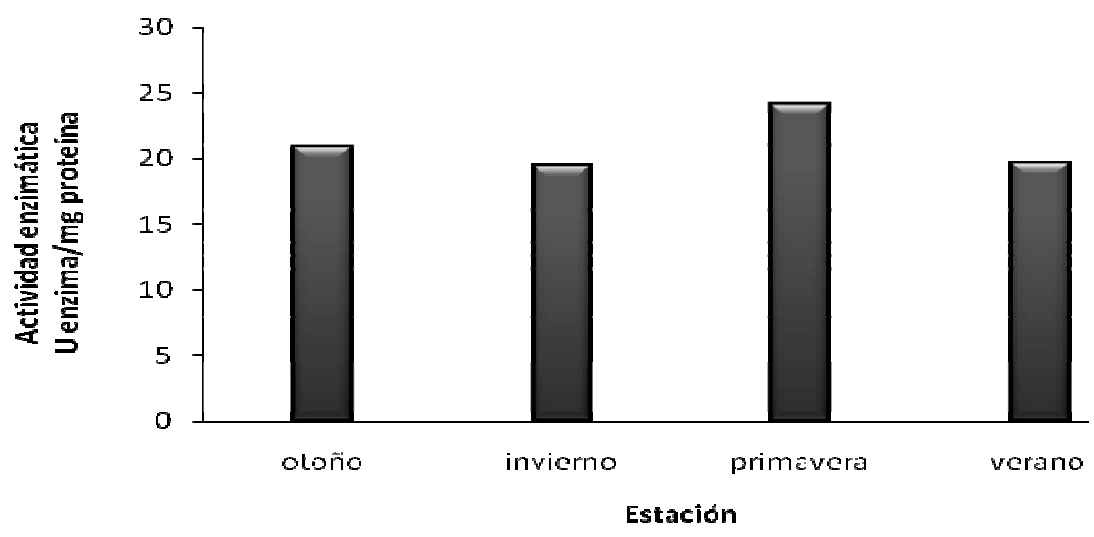

Fig. 6: Actividad enzimática de látex de papayuelo en las distintas estaciones del año, en U/mg de enzima.

Tabla 4: Características de látex de papayuelo (Vasconcellea cundinamarcensis) durante las estaciones del año registradas en Cobquecura el año 2003. (Letras iguales en sentido horizontal no presentan diferencia estadística significativa).

\begin{tabular}{|l|l|l|l|l|}
\hline \multirow{2}{*}{ Característica } & \multicolumn{4}{|c|}{ Estaciones } \\
\cline { 2 - 5 } & Otoño & Invierno & Primavera & Verano \\
\hline Densidad (g/cc) & $0,828 \mathrm{~A}$ & $0,876 \mathrm{~A}$ & $0,973 \mathrm{~A}$ & $0,942 \mathrm{~A}$ \\
\hline Materia seca (\%) & $18,83 \mathrm{~A}$ & $22,7 \mathrm{~A}$ & $20,72 \mathrm{~A}$ & $20,5 \mathrm{~A}$ \\
\hline Sólidos solubles ( ${ }^{\circ}$ Brix) & $24,95 \mathrm{~A}$ & $24,02 \mathrm{~A}$ & $24,63 \mathrm{~A}$ & $23,92 \mathrm{~A}$ \\
\hline $\mathrm{pH}$ & $6,79 \mathrm{~A}$ & $5,95 \mathrm{~A}$ & $6,36 \mathrm{~A}$ & $6,52 \mathrm{~A}$ \\
\hline Acidez titulable (\% ác. cítrico) & $20,2 \mathrm{~A}$ & $35,8 \mathrm{~A}$ & $17,9 \mathrm{~A}$ & $21,8 \mathrm{~A}$ \\
\hline Proteína Bradford (\%) & $0,9022 \mathrm{~A}$ & $0,9 \mathrm{~A}$ & $0,995 \mathrm{~A}$ & $0,941 \mathrm{~A}$ \\
\hline Rendimiento (mL/árbol) & $0 \mathrm{C}$ & $13,369 \mathrm{~A}$ & $12,180 \mathrm{~A}$ & $5,761 \mathrm{~B}$ \\
\hline Actividad enzimática (U/mg enzima) & $20,84 \mathrm{~A}$ & $19,43 \mathrm{~A}$ & $24,13 \mathrm{~A}$ & $19,64 \mathrm{~A}$ \\
\hline Color (moda) & $7,5 \mathrm{YR} / 9 / 2$ & $7,5 \mathrm{YR} / 9 / 2$ & $7,5 \mathrm{YR} / 9 / 2$ & $\begin{array}{l}7,5 \mathrm{YR} / 8- \\
\text { (m/2-4 }\end{array}$ \\
\hline
\end{tabular}

\section{Análisis por sexo}

Se encontró diferencia estadística significativa entre plantas femeninas y hermafroditas en cuanto al número de frutos verdes (Clase I), pequeños (Clase II) y totales por planta, no así en el caso de número de frutos maduros (Clase III), categoría que se mantiene constante en plantas de ambos sexos. En todos los casos en que existe diferencia estadística significativa, las plantas de sexo femenino presentan mayor número de frutos como se muestra en la Tabla 6.

En el papayuelo existen plantas masculinas y plantas femeninas, así como plantas que poseen flores hermafroditas. Estas últimas producen una menor cantidad de frutos (Tabla 6). Para Carica papaya (Huet et al., 2008) se han descrito diferentes tipos de flores que determinan variaciones en la forma del fruto.

En términos generales, las flores son pequeñas, blancas o crema-amarillentas, muy fragantes, aparecen una o más de ellas en forma de racimos sobre la inserción de los pecíolos, pero generalmente una sola de ellas desarrolla fruto. Las flores femeninas tienen forma oval alargada, una corola de cinco pétalos separados, sin estambres. Los cinco carpelos están soldados, dando lugar a un ovario corto y elipsoidal, pentalocular en Vasconcellea cundinamarcensis (a diferencia de Carica papaya, que posee ovario unilocular), con placentación parietal. 
Tabla 5: Características de fruto verde de papayuelo (Vasconcellea cundinamarcensis) (Letras iguales en sentido horizontal no presentan diferencia estadística significativa)

\begin{tabular}{|l|c|c|c|c|}
\hline \multirow{2}{*}{ Características } & \multicolumn{4}{|c|}{ Estaciones } \\
\cline { 2 - 5 } & Otoño & Invierno & Primavera & Verano \\
\hline Materia seca (\%) & $26 \mathrm{C}$ & $23,5 \mathrm{C}$ & $42,17 \mathrm{~B}$ & $78,5 \mathrm{~A}$ \\
\hline Sólidos solubles ( $\left.{ }^{\circ} \mathrm{Brix}\right)$ & $5,5 \mathrm{~A}$ & $4,95 \mathrm{~A}$ & $4,96 \mathrm{~A}$ & $5,33 \mathrm{~A}$ \\
\hline $\mathrm{pH}$ & $5,3 \mathrm{~A}$ & $5,4 \mathrm{~A}$ & $4,7 \mathrm{~A}$ & $4,5 \mathrm{~A}$ \\
\hline $\begin{array}{l}\text { Acidez titulable (\% Ac. } \\
\text { Cítrico) }\end{array}$ & $20 \mathrm{AB}$ & $14,5 \mathrm{~B}$ & $20,17 \mathrm{AB}$ & $27,50 \mathrm{~A}$ \\
\hline Proteína Bradford (\%) & $0,45 \mathrm{AB}$ & $0,71 \mathrm{~B}$ & $0,56 \mathrm{AB}$ & $1,62 \mathrm{~A}$ \\
\hline Proteína Kjeldahl (\%) & $12,78 \mathrm{AB}$ & $15,75 \mathrm{~A}$ & $13,92 \mathrm{AB}$ & $11,37 \mathrm{~B}$ \\
\hline $\begin{array}{l}\text { Actividad enzimática (U/mg } \\
\text { enzima) }\end{array}$ & $5,47 \mathrm{~A}$ & $4,03 \mathrm{~A}$ & $4,18 \mathrm{~A}$ & $7,20 \mathrm{~A}$ \\
\hline $\begin{array}{l}\text { Color (moda) } \\
\text { (10 }\end{array}$ & $\begin{array}{c}5 \mathrm{GY} / 4-6 / 4- \\
10\end{array}$ & $\begin{array}{c}5 \mathrm{GY} / 4-6 / 4- \\
10\end{array}$ & $\begin{array}{c}5 \mathrm{GY} / 4-6 / 4- \\
10\end{array}$ & $\begin{array}{c}5 \mathrm{GY} / 4-6 / 8- \\
10\end{array}$ \\
\hline
\end{tabular}

Tabla 6: Número de frutos Clase I, II, III y totales presentes en plantas femeninas y hermafroditas de papayuelo. Letras iguales en sentido vertical no presentan diferencia significativa entre sexos (test de Duncan, $\mathrm{P} \geq 0.05$ ).

\begin{tabular}{|l|c|c|c|c|}
\hline \multirow{2}{*}{ Sexo } & \multicolumn{4}{|c|}{ Clase } \\
\cline { 2 - 5 } & I (verdes) & II (pequeños) & III (maduros) & totales \\
\hline Femenino & $31,09 \mathrm{~A}$ & $14,44 \mathrm{~A}$ & $0,77 \mathrm{~A}$ & $46,4 \mathrm{~A}$ \\
\hline Hermafrodita & $9,6 \mathrm{~B}$ & $3,4 \mathrm{~B}$ & $0,57 \mathrm{~A}$ & $13,57 \mathrm{~B}$ \\
\hline
\end{tabular}

\section{CONCLUSIONES}

La caracterización de fruto verde y látex de papayuelo (Vasconcellea cundinamarcensis), demuestra que ambos mantienen cualidades uniformes a través del tiempo. No obstante, al comparar el tamaño de fruto verde en las distintas épocas del año, se evidencia que existe diferencia significativa entre estaciones, registrándose el mayor tamaño de fruto en primavera.

El rendimiento de látex presenta cambios durante el año, que establecen una diferencia significativa, entregando una pauta de comportamiento válido para un huerto manejado en condiciones similares al utilizado para este estudio, principalmente en cuanto al objetivo de producción, que contempla la extracción de látex como una posibilidad de actividad complementaria a la producción de fruta y no como actividad exclusiva. Bajo ese contexto, se puede afirmar que el rendimiento más alto se obtiene en primavera, registrándose en otoño ausencia de látex, pues en esa estación no hubo frutos verdes aptos para la extracción. Además, en primavera también se produce un aumento en la altura y diámetro de tronco de las plantas, que se traduce en una mayor producción de látex.

La actividad enzimática fue constante en las estaciones y no mostró diferencia significativa entre ellas. Esta actividad, que llegó a $24.13 \mathrm{U} / \mathrm{mg}$ enzima en primavera, se considera alta, al compararla con patrones de papaína comercial. Tomando en cuenta esta característica del látex, no habría limitante en ninguna época del año para obtener una buena actividad enzimática. Por ello hay que discriminar la mejor época de extracción según otras condiciones, como lo es el rendimiento de látex y las condiciones climáticas más adecuadas para la extracción. En ambos casos la mejor época es primavera. 
Las plantas femeninas resultaron mejores para la extracción de látex, por presentar mayor número de frutos verdes que aquellas hermafroditas. Por ello se obtiene de ellas un mayor rendimiento y además, por la forma del fruto con surcos entre los lóbulos menos pronunciados, los cortes en la superficie del fruto son más limpios y por lo tanto, la extracción se facilita.

\section{AGRADECIMIENTOS}

Este trabajo está subvencionado por el Proyecto DIUC de la Dirección de Investigación de la Universidad de Concepción, código: 203.134.002-1.0. Los autores agradecen las sugerencias realizadas por los correctores anónimos.

\section{REFERENCIAS}

Acosta-Zamudio, C., y otros tres autores.; Respuesta de las plantas de papayo al diferente número de frutos por planta. I. Distribución de biomasa, Revista Chapingo-Serie Horticultura: 5 (2), 131-135 (1999).

AOAC (Association of Official Analytical Chemist), Official methods of analysis of AOAC international, $16^{\text {th }}$ ed, AOAC. Int. Maryland, USA (1995).

Badillo, V.M.; Caricaceae. Segundo Esquema, Alcance: 43, 1-111 (1993).

Badillo V.M.; Carica L. vs. Vasconcella St. Hil. (Caricaceae) con la rehabilitación de este último, Ernstia: 10, 74-79 (2000).

Badillo V.M.; Nota correctiva Vasconcellea St. Hill. y no Vasconcella (Caricaceae), Ernstia: 11, 75-76 (2001).

Baeza, G., D. Correa y C.E. Salas; Proteolytic enzymes in Carica candamarcensis, J. Sci. Food Agric.: 51, 1-9 (1990).

Bradford, M.; A rapid sensitive method for the quantitation of microgram protein utilizing the principle of protein - dye binding, Anal. Biochem.: 72, 248-254 (1976).

Buzeta, P.A. y C. Eyheralde; Efectos de la ubicación geográfica, época de cosecha, sexo y edad de la planta sobre la calidad de la papaya (Carica candamarcensis Hook. f.). Tesis Lic. Cien. Agr. Universidad de Chile, Fac. Cienc. Agrar. Vet. For. Santiago, Chile (1982).

Chavarro, L., C. Ochoa y A. Ayala; Efecto de la madurez, geometría y presión sobre la cinética de transferencia de masa en la deshidratación osmótica de papaya (Carica papaya L. var. Maradol), Ciênc. Tecnol. Aliment., Campinas: 26(3), 596-603 (2006).

Gomes M. T. y otros siete autores; Purification, crystallization and preliminary X-ray analysis of CMS1MS2: a cysteine proteinase from Carica candamarcensis latex, Acta Crystallogr. Sect. F. Struct. Biol. Cryst. Commun.: 64(6), 492-494 (2008).

Hart, F.L. y Fischer, H.J., Análisis Moderno de los Alimentos, 9-22. Acribia, Zaragosa, España (1971).

Huet, J. y otros cuatro autores; Crystallization and preliminary X-ray analysis of a family 19 glycosyl hydrolase from Carica papaya latex, Acta Cryst.: 64, 371-374(2008).

Jobin-Décor, M.P. y otros tres autores; RAPD and isozyme analysis of genetic relationships between Carica papaya and wild relatives, Genetic Resources and Crop Evolution: 44, 471-477 (1997).

Kiger, M.; La papaya, alternativas de industrialización, Chile Hortofrutícola: 2(10), 39-42 (1988).

Kyndt, T., y otros cinco autores; Species relationships in the genus Vasconcellea (Caricaceae) based on molecular and morphological evidence, Amer. J. Bot.: 92, 1033-1044 (2005). 
Larson, S.J. y otros cuatro autores; Papain adulteration in 11-nor-Delta9-tetrahydrocannabinol- 9carboxylic acid-positive urine samples, J. Anal. Toxicol.: 32(6), 438-43(2008).

Montgomery, D.C. y G.C. Runger, Probabilidad y Estadística Aplicadas a la Ingeniería, pp 625-685 McGraw-Hill, México (1998).

Munsell, A.H.; A Color Notation Munsell Color Co, Baltimore (1963).

Quintanilla, Y.D.; Caracterización de la papaya (Carica pubescens Lenné et Koch) de Cobquecura para aptitud industrial. Memoria de título. Ing. Agrón. Universidad de Concepción, Fac. Agron. Chillán, Chile (1995).

Sudzuki, F.; Frutales Subtropicales para Chile, Edit. Universitaria, Santiago. Chile (1996).

Teixeira, R. y otros cuatro autores; The proteolytic activities in latex from Carica candamarcensis, Plant Physiol. Biochem.: 46(11), 956-961 (2008).

Van Droogenbroeck B. y otros ocho autores; Phylogenetic analysis of the highland papayas (Vasconcellea) and allied genera (Caricaceae) using PCR-RFLP, Theoret. Appl. Genetics: 108, 14731486 (2004).

Vega, M.; Obtención purificación e inmovilización de papaína. Tesis Mg. Sc. Nutrición Humana, Universidad de Chile, Inst.Nutr. Tecnol. Alim. Santiago, Chile (1977).

Worthington Biochemical Corporation. Papain dissociation system. Worthington Enzyme Manual (en línea), 1993. Worthington Biochemical Corporation. New Yersey, U.S.A. http://www.worthingtonbiochem.com/pap/default.html. Acceso: 23 de Diciembre (2008).

Yagnam, F.; El cultivo de papayo y extracción de látex, Chile Hortofrutícola: 8(42), 40-46 (1996). 